\title{
Comparison of Different Methods of Multislice Spiral Computed Tomography for the Preoperative Gastric Cancer Staging
}

\author{
Kristina Zviniene1, Irena Krasnovaite1, Mindaugas Kiudelis ${ }^{2 *}$ \\ ${ }^{1}$ Clinic of Radiology, Medicine Academy, Lithuanian University of Health Sciences, Kaunas, Lithuania \\ ${ }^{2}$ Clinic of Surgery, Medicine Academy, Lithuanian University of Health Sciences, Kaunas, Lithuania \\ Email: kristinazviniene@gmail.com, irute.krasnovaite@gmail.com,
}

Received 31 August 2015; accepted 25 September 2015; published 28 September 2015

Copyright (C) 2015 by authors and Scientific Research Publishing Inc.

This work is licensed under the Creative Commons Attribution International License (CC BY). http://creativecommons.org/licenses/by/4.0/

(c) (i) Open Access

\begin{abstract}
Background: To evaluate the diagnostic possibilities of multislice spiral computed tomography (MSCT) in preoperative gastric cancer staging. Methods: A total of 108 patients who had radical gastric cancer surgery were evaluated with MSCT two weeks before surgery in two different stomach imaging methods (water or urographin aqueous solution). Tumor staging was evaluated using the Tumor-Node-Metastasis (TNM) staging. The results from the imaging modalities were compared with the postoperative histopathological outcomes. Results: CT scanning with stomach contrast agent is more accurate $(p<0.05)$ and specific $(p=0.001)$ in determining stage $T 2$; however hydrodynamic method is more sensitive $(p<0.005)$ and has higher PPV $(p<0.005)$. For stage $T 3$, there was no significant difference between accuracy, positive and negative prognostic values; scanning with stomach contrast was more sensitive $(p=0.016)$, and hydrodynamic method was more specific $(p=0.026)$. For stage $T 4$, hydrodynamic method was more sensitive $(p=0.028)$, but there was no significant difference between accuracy, specificity, positive and negative prognostic values. Conclusions: According to our study results, CT scanning with contrast agent is more accurate and specific in preoperative determination of gastric cancer $\mathrm{T} 2$ stage; however hydrodynamic method is more sensitive in preoperative T3 stage determination. We find no significant difference between positive and negative prognostic values of these methods. Scanning with contrast agent was more sensitive, and hydrodynamic method was more specific. Hydrodynamic method is more sensitive in determining gastric cancer T4 stage. CT scan is informative in preoperative gastric cancer $\mathrm{M}$ staging; however it is not informative enough for preoperative $\mathrm{N}$ staging.
\end{abstract}

\section{Keywords}

Gastric Cancer, Preoperative CT Scan Staging

\footnotetext{
${ }^{*}$ Corresponding author.
}

How to cite this paper: Zviniene, K., Krasnovaite, I. and Kiudelis, M. (2015) Comparison of Different Methods of Multislice Spiral Computed Tomography for the Preoperative Gastric Cancer Staging. Surgical Science, 6, 427-435. 


\section{Background}

Gastric cancer is one of the most common malignancies and the second most common cause of cancer death, causing 3\% - 10\% cancer deaths [1]. In Lithuania, this is the fourth most common malignancy among males and the sixth most common among females. Adenocarcinoma accounts for $85 \%-90 \%$ of all stomach malignancies. It is most common among 60 - 75 year patients. In Lithuania, in 1992-2008 the incidence of gastric cancer dropped from 1142 to 836 new cases per year, and in 2008-2011 the incidence was ranging between 934 and 867 new cases per year [2]. Unfortunately, early stages of disease are asymptomatic and the majority of new cases are at stage III-IV. Five-year survival of gastric cancer diagnosed in stage IV is $7 \%-27 \%$; however for early stage it is $85 \%-100 \%$ [3].

Surgery is the mainstay of treatment for resectable gastric cancer. Surgical resection of the primary tumor and regional lymph nodes is a key step in curative treatment. Long-term follow-up results from a Dutch trial demonstrated the advantages of D2 vs. D1 dissection for gastric cancer [4], so these results recommended D2 lymphadenectomy as the procedure of choice for patients with resectable gastric cancer worldwide. In Lithuania, D2 gastrectomy is the standard surgical procedure also.

However, a sizable proportion of gastric cancer patients with stages II and III (moderately advanced) disease develop recurrence after curative D2 gastrectomy. Improved patients outcomes therefore require effective additional treatment options for resectable gastric cancer. In East Asia, D2 surgical resection is followed by adjuvant oral fluoropyrimidine-based therapy [5], whereas a perioperative approach with intensive combination chemotherapy given before and after surgery is conducted in the United Kingdom and parts of Europe [6] including Lithuania. Adjuvant chemoradiotherapy is commonly used following D0/1 surgery for patients with gastric cancer in the United States [7].

Endoscopic ultrasonography and multislice spiral computed tomography are the most common techniques for the preoperative staging of gastric cancer patients. Precise preoperative staging is very important in selecting the most suitable treatment tactics in these patients.

Nowadays computed tomography is the most popular diagnostic method to evaluate the dissemination of tumor and the stage of disease before the surgery [8]. This method allows diagnosing the tumor itself, its metastases in other organs, and local and distant lymph nodes, to evaluate the local spread of the tumor into adjacent organs and tissues [9] [10].

The aim of our study was to compare the diagnostic possibilities of different methods of MSCT scanning in TNM staging, in order to determine the optimal preoperative diagnostic method in patients with gastric cancer.

\section{Materials and Methods}

This was a prospective randomized clinical study, in which 108 patients with resectable gastric cancer were studied. Patients were treated in clinic of surgery during January 2011-December 2013 years. All patients gave their written informed consent, and The Kaunas Regional Biomedical Research Ethics Committee approved the study (protocol no. BE-2-65). Before the surgery, endoscopic examination of stomach was performed and diagnosis of gastric cancer was proved histologically. After this, CT was performed in all patients in clinic of radiology, using multiple-slice CT (“GE Light Speed Pro 64"). The patients were randomized in to two groups according CT scanning technique (stomach imaging). We wanted to determine, which CT stomach scanning technique (hydrodynamic gastric scan or CT scan with contrast agent), is more informative in detecting neoplastic stomach changes.

The first group patients (hydrodynamic - 52 cases) were scanned using water as stomach contrast agent. These patients were drinking $750 \mathrm{ml}$ of water on empty stomach $15 \mathrm{~min}$ before the scanning and $250 \mathrm{ml}$ of water immediately before the scanning. Antiperistalsis drug sol. buscopani $20 \mathrm{mg} / 1 \mathrm{ml}$ was administrated intravenously. $100 \mathrm{ml}$ of non-ionic contrast agent was administrated intravenously (injection speed $\sim 3.5 \mathrm{ml} / \mathrm{s}$ ). Patients were lying on the back, hands above the head, native and contrast scans were obtained in craniocaudal direction. We performed arterial phase scan in 30 sec. and venous phase scan in 60 - 70 sec. Slices were obtained every $2.5 \mathrm{~mm}$.

The second group patients (contrast-56 cases) were scanned using 20\% urographin aqueous solution as stomach contrast agent. Patients were drinking $400 \mathrm{ml}$ of contrast solution on empty stomach immediately before the scanning. Other scanning modalities were the same as in the first group. Different methods of stomach imaging affect only $\mathrm{T}$ staging, however they have no influence on $\mathrm{M}$ and $\mathrm{N}$ staging. 
During the study on CT scans, we analyzed tumor localization, stomach wall, adjacent fatty tissue, contrast enhancement, invasion into adjacent structures, distant metastases, as well as lymph nodes, their size, structure, quantity and contrast enhancement.

To adjust and systematize the radiological evaluation of gastric tumor, we repeatedly analyzed CT scans of every patient according to respectively selected radiological criteria. The main features of $\mathrm{T}$ stage are present in Table 1.

$\mathrm{N}$ staging: Regional lymph nodes are considered involved when the short-axis diameter is $>6 \mathrm{~mm}$ for the perigastric lymph nodes and $>8 \mathrm{~mm}$ for the extraperigastric lymph nodes; other criteria for malignant involvement include a nearly round shape (longitudinal-transverse diameter ratio $<1.5$ ), a fatty hilum that is eccentric or missing, and marked or heterogeneous enhancement. N0 - no signs of metastases in local lymph nodes. N1there are metastases in 1 - 2 local lymph nodes. N2 - there are metastases in 2 - 6 local lymph nodes. N3-there are metastases in $>6$ local lymph nodes (Figure 1).

M staging: M0 -no distant metastases. M1-there are distant metastases (ex., liver, peritoneal carcinosis, distal lymph nodes, lungs, brain, bones and etc.). M1 stage was diagnosed when one of the following detected: metastases in parenchymal organs or distal lymph nodes or peritoneal dissemination.

After preoperative radiological evaluation, all the patients underwent radical surgical treatment (D2 gastrectomy or D2 subtotal gastrectomy according tumor localization and preoperative histology findings) with further histopathological examination of obtained specimens. The results of CT scans were compared with results of surgery and histopathological examination. Pathologic TNM staging system of stomach cancer in the 7th edition of UICC cancer staging system is present in Table 2.

Table 1. CT criteria for gastric cancer T staging.

\begin{tabular}{|c|c|c|c|c|}
\hline T stage & Stomach wall & Fatty tissue infiltration & $\begin{array}{c}\text { Invasion into } \\
\text { adjacent organs }\end{array}$ & Contrast enhancement \\
\hline T1 & $\begin{array}{c}\text { Local thickening of internal wall } \\
>5 \mathrm{~mm} \text {, external layer is intact and is } \\
\text { visualized as a strip of lower density. } \\
\text { Tumor infiltrates mucosa or submucal } \\
\text { layer. }\end{array}$ & $\begin{array}{l}\text { Adjacent fatty tissue is well } \\
\text { differentiated, no infiltration is } \\
\text { observed. }\end{array}$ & None & $\begin{array}{l}\text { Contrast enhancement is } \\
\text { more intensive than in } \\
\text { other parts of stomach } \\
\text { mucosa. }\end{array}$ \\
\hline $\mathbf{T} 2$ & $\begin{array}{c}\text { Tumor is observed as local or diffuse } \\
\text { thickening of the wall, involving } \\
\text { transmural layer. External layer is intact. } \\
\text { Tumor infiltrates muscular and } \\
\text { subserosal layers. }\end{array}$ & $\begin{array}{l}\text { Adjacent fatty tissue is well } \\
\text { differentiated, no infiltration is } \\
\text { observed. }\end{array}$ & None & $\begin{array}{l}\text { Contrast enhancement is } \\
\text { more intensive than in } \\
\text { other parts of stomach } \\
\text { mucosa. }\end{array}$ \\
\hline T3 & $\begin{array}{l}\text { Transmural tumor with uneven or } \\
\text { nodulated involved external layer of the } \\
\text { stomach. Tumor infiltrates serosal layer. }\end{array}$ & $\begin{array}{l}\text { The differentiation of tumor-adjacent } \\
\text { fatty tissue is poor. }\end{array}$ & None & \\
\hline T4 & $\begin{array}{l}\text { Wide tumor infiltration. Tumor } \\
\text { infiltrates adjacent structures. }\end{array}$ & $\begin{array}{l}\text { No differentiation of adjacent fatty } \\
\text { tissue. It is infiltrated. }\end{array}$ & Present & \\
\hline
\end{tabular}

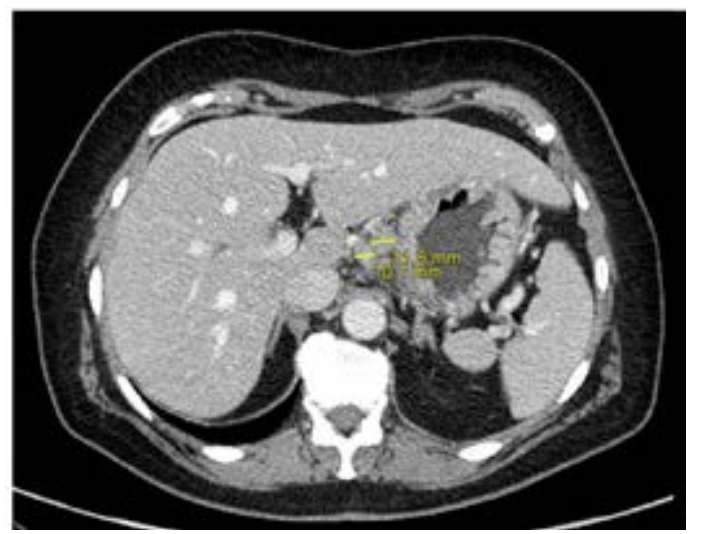

Figure 1. CT scan: enlarged perigastral lymph nodes are observed-N3. 
Table 2. Pathologic TNM staging system of stomach cancer in the 7th edition of UICC cancer staging system.

\begin{tabular}{ccl}
\hline TNM & Stage & \\
\hline T & T1a & Tumor invades lamina propria or muscularis mucosae \\
& T1b & Tumor invades submucosa \\
T2 & Tumor invades muscularis propria \\
& T3 & Tumor penetrates subserosal connective tissue without invasion of visceral peritoneum or adjacent structures \\
& T4a & Tumor invades serosa (visceral peritoneum) \\
& T4b & Tumor invades adjacent structures \\
N & N0 & No regional lymph node metastasis \\
& N1 & Metastasis in 1 - 2 regional lymph nodes \\
& N2 & Metastasis in 3 - 6 regional lymph nodes \\
& N3 & Metastasis in seven or more regional lymph nodes \\
M & M0 & Distant metastasis absent \\
& M1 & Distant metastasis present \\
\hline
\end{tabular}

\section{Statistical Analysis}

The results of preoperative staging using different methods of multislice spiral computed tomography were compared to the postoperative histological diagnosis. The chi-square test or Fisher's exact test was used. A $P$-value less than 0.05 were considered statistically significant. To determine diagnostic values of CT, we calculated the accuracy, sensitivity, and specificity of this investigation, as well as positive and negative prognostic values. Calculations were performed using formulas:

Accuracy of diagnostic method (percentage $)=\mathrm{a}+\mathrm{d} / \mathrm{a}+\mathrm{b}+\mathrm{c}+\mathrm{d} \times 100$

Sensitivity of diagnostic method (percentage) $=a /(a+c) \times 100$

Specificity of diagnostic method (percentage) $=\mathrm{d} /(\mathrm{b}+\mathrm{d}) \times 100$

Positive predictive value $=\mathrm{a} /(\mathrm{a}+\mathrm{b}) \times 100$

Negative predictive value (percentage) $=\mathrm{d} /(\mathrm{c}+\mathrm{d}) \times 100$

where: a - fairly positive cases, $\mathrm{b}$ - false positive cases, $\mathrm{c}$ —-false negative values, $\mathrm{d}$ - fairly negative values.

All calculations were performed using SPSS 16.0 for Windows software (SPSS, Chicago).

\section{Results}

108 gastric cancer patients were enrolled in this study: 66 (66\%) males and 42 (39\%) females. Patient's age distribution was normal. There was no significant difference between male and female age. The group included 3 patients with early gastric cancer and 105 patients with advanced gastric cancer. The clinical and pathological characteristics of the enrolled patients are summarized in Table 3.

There was no cancerous stomach wall lesion on CT scans in $7.4 \%$ of all cases. In $77.7 \%$ of cases gastric cancer was diagnosed at stage T3 and T4, and only in $2.8 \%$ of cases at stage T1. Preoperative and postoperative histological evaluation revealed adenocarcinomas in all cases.

Table 4 shows accuracy, sensitivity, specificity, positive prognostic value (PPV) and negative prognostic value (NPV) of T staging, using different CT scanning methods of stomach imaging.

Based on CT scan results, stage N0 was the most common (36.1\%), and stage N3 was the lowest (11.1\%). Table 5 shows accuracy, sensitivity, and specificity of CT scan in N staging.

In our study, stage M0 was diagnosed in 61\% of cases, stage M1—in 39\%. Determining stages M0 and M1, all the rates were quite high (Table 6).

\section{Discussion}

To improve overall survival, several treatment strategies for resectable gastric cancer have been evaluated. These include postoperative adjuvant chemotherapy, adjuvant chemoradiotherapy, and perioperative chemotherapy. 
Table 3. Clinical and pathological characteristics of enrolled patients.

\begin{tabular}{|c|c|}
\hline Clinical and pathological characteristics & Variable \\
\hline \multicolumn{2}{|l|}{ Age (years) } \\
\hline Range & $35-88$ \\
\hline Median & 66 \\
\hline \multicolumn{2}{|l|}{ Gender } \\
\hline Male & $66(66.1 \%)$ \\
\hline Female & $42(38.9 \%)$ \\
\hline \multicolumn{2}{|l|}{ Tumor location } \\
\hline Cardia & $23(21.3 \%)$ \\
\hline Fundus & $6(5.6 \%)$ \\
\hline Lesser curvature & $20(18.5 \%)$ \\
\hline Greater curvature & $11(10.2 \%)$ \\
\hline Pylorus & $11(10.2 \%)$ \\
\hline >Localization & $37(34.3 \%)$ \\
\hline \multicolumn{2}{|l|}{ Invasion into adjacent organs } \\
\hline None & $77(71.3 \%)$ \\
\hline Liver & $8(7.4 \%)$ \\
\hline Pancreas & $12(11.1 \%)$ \\
\hline Spleen & $1(0.9 \%)$ \\
\hline Left diaphragm & $4(3.7 \%)$ \\
\hline Colon & $2(1.9 \%)$ \\
\hline$>1$ organ & $4(3.7 \%)$ \\
\hline \multicolumn{2}{|l|}{ Metastases } \\
\hline None & $67(62 \%)$ \\
\hline Liver & $10(9.3 \%)$ \\
\hline Carcinosis & $6(5.6 \%)$ \\
\hline Lymph node & $8(7.4 \%)$ \\
\hline Lungs, bones, mediastinum and etc. & $4(3.7 \%)$ \\
\hline >Localization & $13(12 \%)$ \\
\hline \multicolumn{2}{|l|}{ Depth of tumor invasion } \\
\hline Not determined & $8(7.4 \%)$ \\
\hline $\mathrm{T} 1$ & $3(2.8 \%)$ \\
\hline $\mathrm{T} 2$ & $13(12 \%)$ \\
\hline T3 & $52(48.1 \%)$ \\
\hline $\mathrm{T} 4$ & $32(29.6 \%)$ \\
\hline \multicolumn{2}{|l|}{ Lymph node metastasis } \\
\hline No & $39(36.1 \%)$ \\
\hline N1 & $31(28.7 \%)$ \\
\hline N2 & $26(24.1 \%)$ \\
\hline N3 & $12(11.1 \%)$ \\
\hline \multicolumn{2}{|l|}{ Distant metastasis } \\
\hline M0 & $66(61.1 \%)$ \\
\hline M1 & $42(38.0 \%)$ \\
\hline \multicolumn{2}{|l|}{ Surgery } \\
\hline Total gastrectomy & $24(22.22 \%)$ \\
\hline Subtotal gastrectomy & $40(37.04 \%)$ \\
\hline Inoperable tumor & $41(37.96 \%)$ \\
\hline Endoscopic mucosal resection & $3(2.78 \%)$ \\
\hline
\end{tabular}


Table 4. Comparison of preoperative T staging using different stomach imaging methods.

\begin{tabular}{|c|c|c|c|c|c|c|c|c|c|c|c|c|}
\hline & \multicolumn{3}{|c|}{ T1 } & \multicolumn{3}{|c|}{$\mathbf{T} 2$} & \multicolumn{3}{|c|}{ T3 } & \multicolumn{3}{|c|}{ T4 } \\
\hline & $\begin{array}{l}\text { Water } \\
(\mathrm{n}=2)\end{array}$ & $\begin{array}{c}\text { Contrast } \\
(\mathrm{n}=1)\end{array}$ & $\begin{array}{c}\mathbf{p} \\
\text { value }\end{array}$ & $\begin{array}{l}\text { Water } \\
(\mathrm{n}=8)\end{array}$ & $\begin{array}{c}\text { Contrast } \\
(n=5)\end{array}$ & $\begin{array}{c}\mathbf{p} \\
\text { value }\end{array}$ & $\begin{array}{c}\text { Water } \\
(n=22)\end{array}$ & $\begin{array}{c}\text { Contrast } \\
(n=30)\end{array}$ & $\begin{array}{c}\mathbf{p} \\
\text { value }\end{array}$ & $\begin{array}{c}\text { Water } \\
(n=17)\end{array}$ & $\begin{array}{c}\text { Contrast } \\
(\mathrm{n}=15)\end{array}$ & $\begin{array}{c}\mathbf{p} \\
\text { value }\end{array}$ \\
\hline Accuracy (\%) & 83.8 & 90.1 & 0.169 & 83.8 & 95.8 & 0.014 & 83.8 & 78.9 & 0.27 & 89.2 & 80.3 & 0.118 \\
\hline Sensitivity (\%) & 14.3 & 22.2 & 0.162 & 100 & 66.7 & 0.000 & 78.6 & 92.6 & 0.016 & 78.6 & 60.7 & 0.028 \\
\hline Specificity (\%) & 100 & 100 & - & 82.9 & 98.5 & 0.001 & 87 & 70.5 & 0.026 & 95.7 & 93 & 0.288 \\
\hline PPV (\%) & 100 & 100 & - & 25 & 80 & 0.000 & 78.57 & 65.79 & 0.082 & 91.67 & 85 & 0.161 \\
\hline NPV (\%) & 83.3 & 89.86 & 0.162 & 100 & 96.97 & 0.141 & 86.96 & 93.94 & 0.016 & 88 & 78.43 & 0.109 \\
\hline
\end{tabular}

Table 5. Accuracy, sensitivity and specificity of CT scan on N staging.

\begin{tabular}{|cccccccc|}
\hline \multicolumn{7}{c|}{ Histological staging } \\
\hline N stage & $\mathbf{p N 0}(\mathbf{n}=\mathbf{4 9})$ & $\mathbf{p N 1}(\mathbf{n}=\mathbf{3 0})$ & $\mathbf{p N 2}(\mathbf{n}=\mathbf{1 4})$ & $\mathbf{p N 3}(\mathbf{n}=\mathbf{1 5})$ & Accuracy \% & Sensitivity \% & Specificity \% \\
\hline CT N0 & 27 & 7 & 5 & - & $50(54 / 108)$ & $55.1(27 / 49)$ & $45.8(27 / 59)$ \\
CT N1 & 10 & 13 & 3 & 5 & $67.6(73 / 108)$ & $43.3(13 / 30)$ & $76.9(60 / 78)$ \\
CT N2 & 10 & 7 & 6 & 3 & $74.1(80 / 108)$ & $42.9(6 / 14)$ & $78.7(74 / 94)$ \\
CT N3 & 2 & 3 & - & 7 & $88(95 / 108)$ & $46.7(7 / 15)$ & $94.6(88 / 93)$ \\
\hline
\end{tabular}

Table 6. Accuracy, sensitivity and specificity of CT scan in determining distant metastasis.

\begin{tabular}{cccccc}
\hline \multicolumn{7}{c}{ Histological staging } \\
\hline M stage & pM0 $(\mathbf{n}=\mathbf{6 2})$ & $\mathbf{p M 1}(\mathbf{n}=\mathbf{4 6})$ & Accuracy \% & Sensitivity \% & Specificity \% \\
\hline CT M0 & 58 & 8 & $88.9(96 / 108)$ & $93.5(58 / 62)$ & $82.6(38 / 46)$ \\
CT M1 & 4 & 38 & $88.9(96 / 108)$ & $82.6(38 / 46)$ & $93.5(58 / 62)$ \\
\hline
\end{tabular}

The most definitive findings from studies are that surgery alone is no longer recommended for resectable gastric cancer. Precise preoperative staging is very important in selecting the most suitable treatment tactics in patients with gastric cancer. In this our study, we tried to compare two different CT scanning techniques of stomach imaging and evaluate the possibility of CT scan in preoperative gastric cancer staging.

The intact wall of adequately stretched stomach should be less than $5 \mathrm{~mm}$ thick. T1a stage gastric tumours are usually not detectable on CT scans, because pathological changes do not differ. T1b stage tumours look like thickening of mucosa with contrast enhancement. T1b and T2 tumours can be differentiated based on CT scans: T1b stage tumours look like thickening of mucosa with lower density stripe at the base of pathological changes, corresponding to submucosa; and there is no such stripe in T2 stage tumours, but vivid and smooth outer layer of gastric wall at the site of pathological changes [11] [12]. Endoscopic ultrasound (EUS) is more accurate in determining especially T1 and les T2 stages [13]. One of the weaknesses of our study is that we didn't perform EUS to the study patients because of the objective reasons (received the device at the end of 2012 year), so we examined the patients only by simple endoscopy.

According our study results, the sensitivity of determining T1 stage on CT scan is low, however, accuracy and specificity are quite high. Accuracy and sensitivity of hydrodynamic method were $83.8 \%$ and $14.3 \%$ respectively, accuracy and sensitivity of scanning with stomach contrast agent were $90.1 \%$ and $22.2 \%$ respectively, specificity of both methods was $100 \%$. The sample of $\mathrm{T} 1$ group is very small, only $2.8 \%$ of tumors were at stage T1, so the results should be interpreted with caution.

The sample of T2 stage tumors is small as well (12\%). For hydrodynamic method, accuracy is $83.8 \%$, sensitivity-100\%, and specificity-82.9\% vs. stomach contrast method, where accuracy—95.8\%, sensitivity$66.7 \%$, and specificity-98.5\%. A larger group of patients with gastric cancer stage T1 and T2 is needed in or- 
der to find the significant diagnostic differences between these two stomach imaging techniques. According the literature [8]-[10], hydrodynamic method is more informative in diagnosing small and early stage tumors, it also allows detecting those tumors earlier, compared to scanning with contrast agent. In addition, adequate stretching of stomach walls is required in order to receive good images.

Our study results demonstrated that the CT scanning with stomach contrast is more accurate $(\mathrm{p}<0.05)$ and specific $(\mathrm{p}=0.001)$ in determining stage T2, however hydrodynamic method is more sensitive $(\mathrm{p}<0.005)$ and has higher PPV $(\mathrm{p}<0.005)$.

T3 stage tumours appear as thickening of the wall with uneven outer layer of gastric wall and/or infiltration of perigastric tissues. According to new $7^{\text {th }}$ UICC T stage classification, it is very difficult to differentiate T3 and T4a stages on CT scans, because serosa is not visible, and subserosa fatty tissue is different in every person. It can also be challenging to differentiate perigastric tissues infiltration in cases of gastric cancer from perigastric inflammation or fibrosis; this is why T2 stage tumours may mimic T3 and T4 stage tumours. Direct tumour spread and its invasion into adjacent tissues and organs correspond with T4b stage tumours [14] [15].

Our study results demonstrated, that for stage T3, there was no significant difference between accuracy, positive and negative prognostic values; scanning with contrast agent was more sensitive $(p=0.016)$, and hydrodynamic method was more specific $(\mathrm{p}=0.026)$.

For stage $\mathrm{T} 4$, hydrodynamic method was more sensitive $(\mathrm{p}=0.028)$, but there was no significant difference between accuracy, specificity, positive and negative prognostic values.

$\mathrm{N}$ staging is as clinically important as $\mathrm{T}$ staging, because it determines surgical treatment and prognosis. However, $\mathrm{N}$ staging on CT scans is complicated and does not depend on imaging technique. According to different authors, accuracy of $\mathrm{N}$ staging varies from $51 \%$ to $83.8 \%$. Other authors claim specificity lower than $62 \%$ [9]. Although size and structure are criteria of pathological lymph nodes, such low accuracy may represent need for new CT criteria of metastatic lymph nodes. Lymph node enlargement can be caused by inflammation, and vice versa, normal-sized lymph nodes can be metastatic (microscopic invasion) [16] [17].

As you can see, sensitivity of N staging based on CT scans is low, as well as accuracy and specificity, especially for stages N0 and N1. Retrospectively analyzing CT scans we noticed, that the results of CT and postoperative-histological evaluation often do not match. In few cases on CT scans we observed multiple parasagital lymph nodes up to $\sim 1.1 \mathrm{~cm}$, so we diagnosed stage N3; however postoperative-histological evaluation determined stage N0. Also in our study, we had few cases when no pathological lymph nodes were visible on CT scans, however histological study revealed stages N1 to N3. We evaluated the size and structure of lymph nodes, which are the standard criteria for pathological lymph nodes, and found that accuracy is very low. Based on our study results and literature review, we can assume that size and structure of lymph nodes are not reliable enough in determining whether they are pathological or not. The implication of new CT criteria for pathological lymph nodes evaluation should be considered (Figure 1).

Most common distant metastases of gastric cancer are in the liver. Less common are in lungs, suprarenal glands, kidneys, bones, brain and digestive system. In case of disseminated gastric cancer, you can see peritoneal metastases that correlate with cancer size and $\mathrm{T}$ stage. It is important to diagnose carcinomatosis before the surgery. CT scan carcinomatosis signs are: ascites, great omentum nodes, thickening and nodes of small intestine walls, intraperitoneal infiltration of fatty tissue, contrast enhancement. Ascites is the predisposing factor of peritoneal metastases. Chang et al. measured the ascites volume on CT scans and found that $\geq 50 \mathrm{~mL}$ of ascites mean carcinomatosis in $75 \%$ - $100 \%$ of patients [18]. According to Yajima et al., sensitivity of peritoneal metastases is $51 \%$, and specificity is $97 \%$ [19].

Our study results of preoperative gastric cancer $\mathrm{T}$ and $\mathrm{N}$ staging are very similar to those reported in the literature [20] [21].

\section{Conclusion}

According our study results, CT scanning with contrast agent is more accurate and specific in preoperative determination of gastric cancer stage T2; however hydrodynamic method is more sensitive in preoperative T3 stage determination. We find no significant difference between positive and negative prognostic values of these methods. Scanning with contrast agent was more sensitive, and hydrodynamic method was more specific. Hydrodynamic method is more sensitive in determining gastric cancer stage T4. CT scan is informative in preoperative gastric cancer $\mathrm{M}$ staging; however it is not informative enough for preoperative $\mathrm{N}$ staging. 


\section{Competing Interests}

The authors declare that they have no competing interests.

\section{Author's Contributions}

KZ, IK, MK collected, analysed and interpreted the data. KZ, MK drafted the study concept and design, supervised the study, analysed and interpreted the data. IK, MK drafted the manuscript. All authors read and approved the final manuscript.

\section{References}

[1] Proškutè, D., Poškus, T. and Jovaišas, V. (2011) Videoasistuojamosios mediastinoskopijos panaudojimas ir reikšmė nustatant skrandžio kardialinès dalies adenokarcinomos priešoperacinę stadiją: 2 klinikinių atvejų analizè. Sveikatos mokslai, 21, 125-130.

[2] Vèžio Registro Centras (2010) Vilniaus Universiteto Onkologijos Instituto vėžio kontrolès ir profilaktikos centras. http://www.vuoi.lt/?457134211

[3] Martin, R.C., Jaques, D.P., Brennan, M.F. and Karpeh, M. (2002) Extended Local Resection for Advanced Gastric Cancer: Increased Survival versus Increased Morbidity. Annals of Surgery, 236, 159-165. http://dx.doi.org/10.1097/00000658-200208000-00003

[4] Songun, I., Putter, H., Kranenbarg, E.M., Sasako, M. and van de Velde, C.J. (2012) Surgical Treatment of Gastric Cancer: 15-Year Follow-Up Results of the Randomized Nationwide Dutch D1D2 Trial. Lancet Oncology, 11, 439-449. http://dx.doi.org/10.1016/S1470-2045(10)70070-X

[5] Bang, Y.J., Kim, Y.W., Yang, H.K., Chung, H.C., Park, Y.K., Lee, K.H., Lee, K.W., Kim, Y.H., Noh, S.I., Cho, J.Y., Mok, Y.J., Kim, Y.H., Ji, J., Yeh, T.S., Button, P., Sirzen, F. and Noh, S.H. (2012) CLASSIC Trial Investigators: Adjuvant Capecitabine and Oxaliplatin for Gastric Cancer after D2 Gastrectomy: A Phase 3 Open-Label, Randomized Controlled Trial. Lancet, 379, 315-321. http://dx.doi.org/10.1016/S0140-6736(11)61873-4

[6] Cunningham, D., Allum, W.H., Stenning, S.P., Thompson, J.N., Van de Velde, C.J., Nicolson, M., Scarffe, J.H., Lofts, F.J., Falk, S.J., Iveson, T.J., Smith, D.B., Langley, R.E., Verma, M., Weede, S. and Chua, Y.J. (2006) MAGIC Trial Participants: Perioperative Chemotherapy versus Surgery Alone for Resectable Gastroesophageal Cancer. New England Journal of Medicine, 355, 11-20. http://dx.doi.org/10.1056/NEJMoa055531

[7] Macdonald, J.S., Smalley, S.R., Benedetti, J., Hundahl, S.A., Estes, N.C., Stemmermann, G.N., Haller, D.G., Ajani, J.A., Gunderson, L.L., Jessup, J.M. and Martenson, J.A. (2001) Chemoradiotherapy after Surgery Compared with Surgery Alone for Adenocarcinoma of the Stomach or Gastroesophageal Junction. New England Journal of Medicine, 345, 725-730. http://dx.doi.org/10.1056/NEJMoa010187

[8] Cidon, E.U. and Cuenca, I.J. (2009) Gastric Adenocarcinoma: Is Computed Tomography (CT) Useful in Preoperative Staging? Clinical Medicine: Oncology, 3, 91-97.

[9] Chen, C.Y., Hsu, J.S., Wu, D.C., Kang, W.Y., Hsieh, J.S., Jaw, T.S., Wu, M.T. and Liu, G.C. (2007) Gastric Cancer: Preoperative Local Staging with 3D Multi-Detector Row CT-Correlation with Surgical and Histopathologic Results. Gastrointestial Imaging, 242, 472-482. http://dx.doi.org/10.1148/radiol.2422051557

[10] Kim, Y., Kim, H.J. and Ha, H.K. (2005) Gastric Cancer by Multidetector Row CT: Preoperative Staging. Abdominal Imaging, 30, 465-472. http://dx.doi.org/10.1007/s00261-004-0273-5

[11] Lee, I.J., Lee, J.M., Kim, H.K., Shin, C.I., Lee, J.Y., Kim, S.H., Han, J.K. and Choi, B.I. (2010) Diagnostic Performance of 64-Channel Multidetector CT in the Evaluation of Gastric Cancer: Differentiation of Mucosal Cancer (T1a) from Submucosal Involvement (T1b and T2). Radiology, 255, 805-814. http://dx.doi.org/10.1148/radiol.10091313

[12] Lee, J.H., Jeong, Y.K., Kim, D.H., Go, B.K., Woo, Y.J., Ham, S.Y. and Yang, S.O. (2000) Two-Phase Helical CT for Detection of Early Gastric Carcinoma: Importance of the Mucosal Phase for Analysis of the Abnormal Mucosal Layer. Journal of Computer Assisted Tomography, 24, 777-782. http://dx.doi.org/10.1097/00004728-200009000-00020

[13] Feng, X.-Y., Wang, W., Luo, G.-Y., Wu, J., Zhou, Z., Li, W., et al. (2013) Comparison of Endoscopic Ultrasonography and Multislice Spiral Computed Tomography for the Preoperative Staging of Gastric Cancer-Results of a Single Institution Study of 610 Chinese Patiens. PLOS ONE, 8, e78846. http://dx.doi.org/10.1371/journal.pone.0078846

[14] Washington, K. (2010) 7th Edition of the AJCC Cancer Staging Manual: Stomach. Annals of Surgical Oncology, 17, 3077-3079.

[15] Kwon, S.J. (2011) Evaluation of the 7th UICC TNM Staging System of Gastric Cancer. Journal of Gastric Cancer; 11, 78-85. http://dx.doi.org/10.5230/jgc.2011.11.2.78

[16] Lee, M.H., Choi, D., Park, M.J. and Lee, M.W. (2012) Gastric Cancer: Imaging and Staging with MDCT Based on the 
7th AJCC Guidelines. Abdominal Imaging, 37, 531-540. http://dx.doi.org/10.1007/s00261-011-9780-3

[17] Dicken, B.J., Bigam, D.L., Cass, C., Mackey, J.R., Joy, A.A. and Hamilton, S.M. (2005) Gastric Adenocarcinoma. Review and Considerations for Future Directions. Annals of Surgery, 241, 27-39.

[18] Chang, D.K., Kim, J.W., Kim, B.K., Shin, C.-I., Lee, J.Y., et al. (2005) Clinical Significance of CT-Defined Minimal Ascites in Patients with Gastric Cancer. World Journal of Gastroenterology, 11, 6587-6592.

[19] Yajima, K., Kanda, T., Ohashi, M., Wakai, T., Nakagawa, S., et al. (2006) Clinical and Diagnostic Significance of Preoperative Computed Tomography Findings of Ascites in Patients with Advanced Gastric Cancer. American Journal of Surgery, 192, 185- 190. http://dx.doi.org/10.1016/j.amjsurg.2006.05.007

[20] Lee, I.J., Lee, J.M., Kim, S.H., Chang, S., Han, J.K., Choi, B.I., Lee, H.J., Yang, H.K., Lee, K.U. and Helical, C.T. (2009) Evaluation of the Preoperative Staging of Gastric Cancer in the Remnant Stomach. American Journal of Roentgenology, 192, 902-908. http://dx.doi.org/10.2214/AJR.07.3520

[21] Kim, H.J., Kim, A.Y., Oh, S.T., Kim, J.S., Kim, K.W., Kim, P.N., Lee, M.G. and Ha, H.K. (2005) Gastric Cancer Staging at Multi-Detector Row CT Gastrography: Comparison of Transverse and Volumetric CT Scanning. Radiology, 236, 879-885. http://dx.doi.org/10.1148/radiol.2363041101 